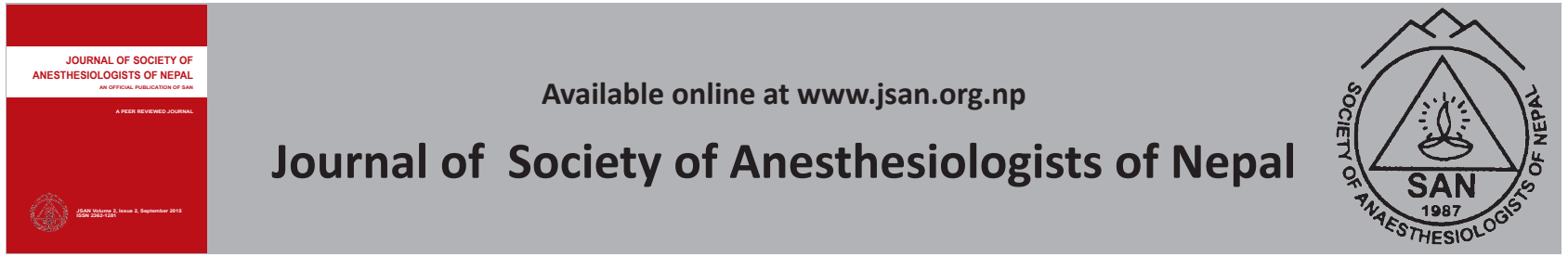

Original article

\title{
Oral midazolam versus oral triclofos for sedation of children for computed tomography scan - a randomized clinical trial
}

Anshu Gupta, Maitree Pandey, Lalita Choudhry, Aruna Jain, Harish Pemde

Lady Harding Medical College, C-604, Shaheed Bhagat Singh Road, Diz Area, Connaught Place, New Delhi,

Delhi 110001, India.

\author{
ARTICLE INFO \\ Article History \\ Received 04.02.2015 \\ Accepted 25.06.2015 \\ Published 10.09.2015 \\ (C) Authors retain copyright \\ and grant the journal right \\ of first publication with the \\ work simultaneously licensed \\ under a Creative Commons \\ Attribution License that allows \\ others to share the work with \\ an acknowledgement of the \\ workss authorship and initial \\ publication in this journal.
}

\begin{abstract}
Background: Effective and safe pediatric procedural sedation is still a concern especially in areas outside operation theatres. The aim of the study was to compare the efficacy and safety of oral triclofos and oral midazolam in children undergoing computed tomography.
\end{abstract}

Methods: A prospective randomized double blind study was conducted in 100 children aged one to five years. Group-I $(n=50)$ received oral triclofos $100 \mathrm{mg} / \mathrm{kg}$ and Group-II $(n=50)$ oral midazolam $0.75 \mathrm{mg} / \mathrm{kg}$. Both groups were given oral atropine $0.03 \mathrm{mg} / \mathrm{kg}$ and supplemented with intravenous midazolam upto $0.1 \mathrm{mg} / \mathrm{kg}$ in case of inadequate effect. Onset and duration of sedation, success for completion of procedure and time to recovery were noted. Student's t test and Z test of proportions were used for statistical analysis.

Results Majority of children 36(72\%) in Group-I achieved Ramsay Sedation Score $>4$ as compared to $25(50 \%)$ in Group-II. Computed tomography scan could be successfully completed at comparable rate ( $52 \%$ vs $56 \%$ ). Success rate improved to $96 \%$ vs $80 \%$ after supplementing intravenous midazolam in Group I \& II respectively $(p<0.05)$. Onset (37.91minutes \pm 7.96 vs $26 \pm 10$ ), duration of sedation ( 117.91 minutes \pm 72.41 vs 66.2 minutes \pm 33 ) were significantly shorter and recovery (98.19minutes \pm 72.58 vs 47.4 minutes \pm 31.42 ) in Group I \& II respectively was faster in children who received oral midazolam $(p<0.05)$.

Conclusion We conclude that both drugs were equally effective and safe for computed tomography scan in children. However better recovery profile of midazolam makes it more suitable for day care procedures.

Keywords: child; midazolam; triclofos; X- ray computed tomography.

How to cite this article: Gupta A, Pandey M, Choudhry L, Jain A, Pemde H. Oral midazolam versus oral triclofos for sedation of children for computed tomography scan - a randomized clinical trial. JSAN 2015;2:41-45.

Corresponding author: Professor Dr Anshu Gupta, DNB

Department of Anesthesiology, Lady Harding Medical College, C-604, Shaheed Bhagat Singh Road, Diz Area,

Connaught Place, New Delhi, Delhi 110001, India

Phone number +919711000264

Email: anug71@yahoo.co.in 


\section{Introduction}

Historically, chloral hydrate and pentobarbital has been the drugs of choice for pediatric sedation in radiology departments. However, these drugs are often associated with prolonged recovery time and sedation related morbidity. ${ }^{1-3}$ Although various combinations of drugs and routes of administration have been used the oral route remains the least threatening method of drug administration in children.

Triclofos is time tested drug for use in pediatric sedation but has variable onset of action and unpredictable long recovery time. ${ }^{4}$ More recently, Oral midazolam is being widely used and found as safe and effective premedication which provides rapid onset and does not prolong recovery room stay. ${ }^{5}$ Various studies have reported safety of oral midazolam in doses ranging from $0.5 \mathrm{mg} / \mathrm{kg}$ to $1.0 \mathrm{mg} / \mathrm{kg}$. ${ }^{5}$ Although higher doses have been used as preanesthetic medication $^{5}$, most of the studies for sedation during radioimaging are mostly limited to doses of $0.5 \mathrm{mg} / \mathrm{kg}$ and results were not found to be good. ${ }^{2,3,6}$ The objective of this study was to compare the safety and efficacy of oral triclofos $100 \mathrm{mg} / \mathrm{kg}$ and oral midazolam $0.75 \mathrm{mg} / \mathrm{kg}$ for sedation in children undergoing computed tomography (CT) scan.

\section{Methods}

The study was conducted in Lady Harding Medical College over a period of sixteen months. Study was approved by institutional Ethical committee. Children of age group one to five years scheduled for CT scan were taken up for the study. Those allergic to the study medications, having respiratory distress, hypotension, liver and kidney disease or who had received a sedative hypnotic agent within the past 48 hours were excluded.

After careful preanaesthetic examination, written informed consent was obtained from the parents. Randomization was done in blocks of 10 using computer generated sequence. Group allocation was kept in serially numbered opaque envelops. Faculty member not involved in the study prepared and administered the drug. Clear mango juice without pulp with colour similar to triclofos was added to injection midazolam and the volume equalized in both groups was one $\mathrm{ml} / \mathrm{kg}$. Investigator observing the patients was blinded to the drug given.

Efficacy was assessed by proportion of children completing the CT scan procedure successfully, proportion of children attaining desired level of sedation, co-operation of children for successful completion of procedure even with less than desired level of sedation and requirement of supplementation by intravenous midazolam. Safety of drug was assessed by occurrence of any adverse event like desaturation, need for assisted ventilation, hypotension and bradycardia.

Patients were kept nil orally for six hours. Study drug was administered in equal volumes as per group allocated. Oral triclofos $100 \mathrm{mg} / \mathrm{kg}$ was given in children in Group-। and oral midazolam $0.75 \mathrm{mg} / \mathrm{kg}$ in Group-II with atropine $0.03 \mathrm{mg} / \mathrm{kg}$ in clear juice. Sedation was assessed every five minutes by Ramsay Sedation Scale ${ }^{7}$ as: 1 . Anxious and agitated or restless or both, 2.Cooperative, oriented and calm, 3.Resposive to commands only, 4. Exhibiting brisk response to light glabellar tap or loud auditory stimulus, 5. Exhibiting sluggish response to light glabellar tap or loud auditory stimulus, 6 . unresponsive.

Patients were taken for scan after they achieved Ramsay Score $>4$ or at one hour irrespective of level of sedation. Patients who were inadequately sedated were supplemented with intravenous (iv) midazolam at the dose of $0.05 \mathrm{mg} / \mathrm{kg}$ repeated after five minutes if still inadequate (upto $0.1 \mathrm{mg} / \mathrm{kg}$ ). If still child did not allow the procedure intravenous ketamine was given.

Safety measures included continuous monitoring of pulse oximetry and intermittent assessment of respiratory rate $(\mathrm{RR})$, heart rate $(\mathrm{HR})$ and blood pressure $(\mathrm{BP})$ to evaluate for cardio-respiratory depression. Recovery was assessed by Aldrete Recovery Score. ${ }^{8}$ Aldrete Score $\geq 8$ was taken as the target for recovery. Study was terminated once recovery criteria were satisfied. Children were discharged as per institutional protocol.

Onset of sedation defined as time from drug administration to time at which Ramsay Score $>4$ was achieved and duration of sedation was defined as time from onset of sedation to time at which recovery (Aldrete Score $>8$ ) was achieved. Both these were noted. Recovery -time from completion of scan to time to achieve Aldrete Score $>8$ was also noted.

Duration of scan, any additional drug given and adverse effects like desaturation, apnoea, hypotension, arrhythmia and nausea/vomiting were also noted.

Primary outcome measure was successful completion of CT scan without rescue sedation. Secondary outcome measures were onset and duration of sedation and time to recovery as well as requirement of rescue sedation.

For calculating sample size, it was presumed that there will be a difference of $20 \%$ in primary outcome variable (i.e. rate of successful CT scan after giving oral drug) in 2 groups. Taking power of study as $80 \%$ and significance level as $5 \%$ ( $p$ value $<0.05$ ), the sample size was calculated. It provided a sample size of 48 subjects in each group and we planned to have 50 subjects in each group. Statistical analysis was done with STATA version 8.0. Z test of proportion was used for comparing proportions and Student's t test was used to compare means between the two groups.

\section{Results}

One hundred patients were included in the study and were equally divided in both groups. Patients in Group-I received triclofos and in Group-II received midazolam orally.

Distribution of age and weight was similar in both groups (Table 1). 
More (72\%) children in triclofos group achieved desired sedation score as compared to midazolam group (50\%). Nearly half children in both groups underwent successful completion of CT scan. Overall success rate for completion of CT scan was comparable in both groups. (Table-1)(Figure-1)

Nine children in midazolam group (Group II) underwent CT scan despite having Ramsay Score $\leq 4$. This was not seen in any child in triclofos group.

With intravenous midazolam as rescue sedation, success rate for completion of procedure improved in both groups ( $96 \%$ vs $80 \%$ in triclofos and midazolam group respectively). The difference was statistically significant with triclofos group having better success rate (Table-1).

Onset and duration of sedation were significantly shorter and recovery faster in midazolam group as compared to triclofos group (Table-1).

All patients remained hemodynamically stable. No serious side effects were noted in either group in our study. None of the sedated patients required oxygen administration, resuscitation, assisted ventilation or intubation.

Table 1: Comparison of study groups

\begin{tabular}{|c|c|c|c|}
\hline & $\begin{array}{l}\text { Triclofos Group(Group- } \\
\text { I) }(n=50)\end{array}$ & $\begin{array}{l}\text { Midazolam Group(Group- } \\
\text { II) }(n=50)\end{array}$ & $\begin{array}{l}\mathbf{P} \\
\text { value }\end{array}$ \\
\hline Mean Age $\pm S D$ (years) & $2.12 \pm 1$ & $2.28 \pm 1.3$ & 0.49 \\
\hline Mean Weight \pm SD (Kg) & $9.16 \pm 2.28$ & $9.26 \pm 2.37$ & 0.83 \\
\hline Males/Females & $29 / 21$ & $42 / 8$ & \\
\hline No. of patients achieving Ramsay Sedation Score $>4$ & $36(72 \%)$ & $25(50 \%)$ & 0.01 \\
\hline $\begin{array}{l}\text { Successful completion of procedure without rescue } \\
\text { medication }\end{array}$ & $26(52 \%)$ & $28(56 \%)$ & 0.34 \\
\hline Completion of procedure with rescue iv midazolam & $22(44 \%)$ & $12(24 \%)$ & 0.01 \\
\hline $\begin{array}{l}\text { Completion of procedure with further addition of iv } \\
\text { ketamine }\end{array}$ & $2(4 \%)$ & $10(20 \%)$ & 0.006 \\
\hline Onset (minutes) (mean \pm SD) & $37.91 \pm 7.96$ & $26 \pm 10$ & 0.000 \\
\hline Duration (minutes) (mean $\pm S D$ ) & $117.91 \pm 72.41$ & $66.2 \pm 33$ & 0.000 \\
\hline Recovery (minutes) (mean \pm SD) & $98.19 \pm 72.58$ & $47.4 \pm 31.42$ & 0.001 \\
\hline$P<0.05$ was considered significant & & & \\
\hline
\end{tabular}

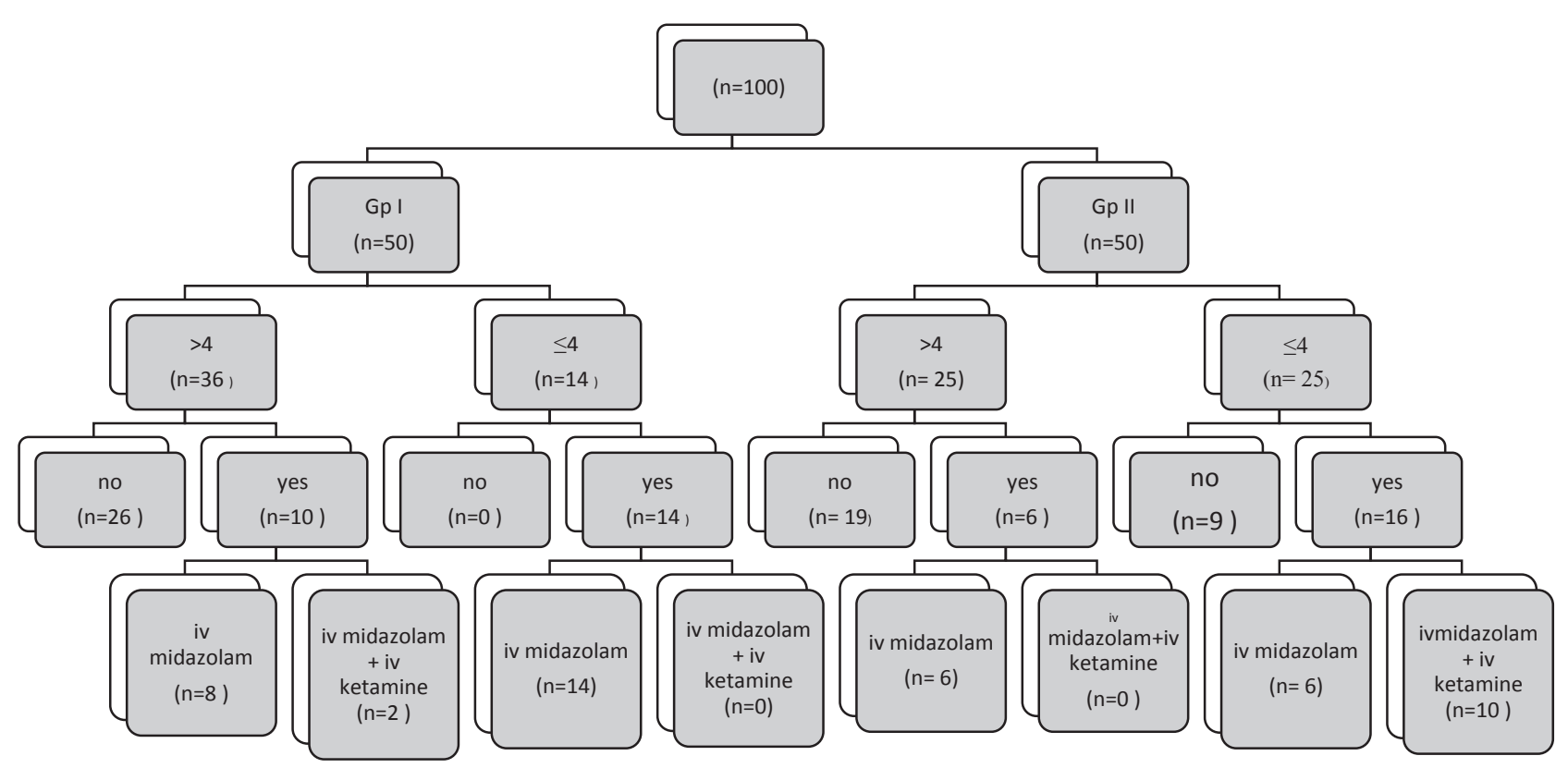

Figure 1: Flowchart of sedation in children for completion of procedure (CT scan) 


\section{Discussion}

We compared oral triclofos and oral midazolam. Both drugs are routinely used in our institution for sedating pediatric patients.

We found that children who received oral triclofos $100 \mathrm{mg} / \mathrm{kg}$ had better sedation than those who received midazolam $0.75 \mathrm{mg} / \mathrm{kg}$. CT scan could be done in both groups at comparable rate.

Success rate improved to $96 \%$ in triclofos group as compared to $80 \%$ in midazolam group after supplementation with intravenous midazolam $(p<0.05)$. Onset and duration of sedation were significantly shorter and recovery faster in midazolam group as compared to triclofos group (Table- 1 ).

Agostino JD used chloral hydrate and found it to be effective. ${ }^{6}$ Triclofos is the phosphate ester of trichloroethanol, the pharmacologically active metabolite of chloral hydrate. It is less gastric irritant and is better accepted orally. Oral triclofos has been successfully used in doses of $75-100 \mathrm{mg} /$ kg. ${ }^{4,9}$ Gozal D reported safe use of $100 \mathrm{mg} / \mathrm{kg}$ triclofos in a hospital over a period of six years for many pediatric procedures outside the operating room. ${ }^{4}$

Oral midazolam is more commonly used as a premedicant drug and has been used in the dose range of 0.25 to 1.0 $\mathrm{mg} / \mathrm{kg}$ in children. ${ }^{5,9,10}$ Various clinical trials have also reported use of oral midazolam in doses of $0.5 \mathrm{mg} /$ $\mathrm{kg}$ in minor procedures, tooth extraction and neuroimaging. ${ }^{11,12,13}$ Higher doses of oral midazolam have been used in pediatric dentistry, echocardiography and in neuro-imaging studies as well. ${ }^{2,13,14}$ We chose the dose of $0.75 \mathrm{mg} / \mathrm{kg}$ oral midazolam for our study.

As syrup preparation was not available we used intravenous midazolam and mixed it with sweet clear mango juice (bottled) to make it palatable. The midazolam is in equilibrium mixture forms, the relative amount of which is $\mathrm{pH}$ dependent. Nonstandard formulations of oral midazolam may result in unpredictable absorption and variable drug dose response..$^{15}$ We could not find any study for standardizing the use of intravenous midazolam preparation orally after mixing it with mango juice. We used mango juice to make it look like triclofos syrup. Same brand of juice was used in all children to make it comparable. We did not do pharmacokinetic studies which might reflect any change in $\mathrm{pH}$ or absorption. The bioavailability of oral midazolam is reported to be $15 \%$ with doses of 0.45 and $1.0 \mathrm{mg} / \mathrm{kg}$ as compared to $87 \%$ with intravenous midazolam. ${ }^{16}$ Onset of action of oral midazolam is longer than intravenous midazolam. That is why patients who were inadequately sedated were supplemented with intravenous midazolam. Safe use of intravenous midazolam in CT scan has been reported at doses at $0.2 \mathrm{mg} / \mathrm{kg} .{ }^{17}$ We gave intravenous midazolam in small aliquots and limited doses up to $0.1 \mathrm{mg} / \mathrm{kg}$ due to prior administration of oral midazolam or triclofos.

Agostino JD used oral midazolam $0.5 \mathrm{mg} / \mathrm{kg}$ for radioimaging procedures and reported $50 \%$ failure rate despite supplementing upto the doses of $0.75 \mathrm{mg} / \mathrm{kg}$ if sedation was inadequate. ${ }^{6}$ Roach $\mathrm{CL}$ also reported $66 \%$ success rate in pediatric sedation for echocardiography with mean oral midazolam doses of $0.8 \mathrm{mg} / \mathrm{kg}^{14}$ Schmalfuss I used oral midazolam in average dose of 0.875 $\mathrm{mg} / \mathrm{kg}$ and reported $43.75 \%$ failure rate. ${ }^{2}$ Similarly in our study $56 \%$ (28) children co-operated for CT scan. Success rate could be improved to $80 \%$ with further iv midazolam supplementation in Group-II (midazolam group).

Parameswari A compared oral triclofos $75 \mathrm{mg} / \mathrm{kg}$ and midazolam $0.5 \mathrm{mg} / \mathrm{kg}$ as preanaesthetic medication. ${ }^{9}$ They found that although sedation and anxiolysis was better in triclofos group but acceptance of facemask was much better in midazolam group. In our study also acceptance of procedure was better in midazolam group, as success rate was similar in both the groups despite achieving better sedation in triclofos group. Nine patients in midazolam group co-operated for procedure without attaining desired level of sedation. This was not seen in any patient in triclofos group.

Gozal D has reported that three patients with triclofos had to be admitted due to prolonged sedation in a large observational study. ${ }^{4}$ In a large prospective study Malviya $S$ has also reported return of three cases to emergency department due to prolonged sedation after receiving triclofos. ${ }^{3}$ In our study onset time and duration of sedation were shorter and recovery was significantly faster in midazolam group as compared to triclofos group. No patient had to be admitted in either group.

Although triclofos produced better sedation but limitation was longer onset and duration of action and slower recovery which is undesirable in day care procedures especially outside operation theatres. Midazolam allowed CT scan to be done in $80 \%$ of children without prolonging recovery room stay.

In our study more children attained satisfactory sedation with oral triclofos; however success rate of procedure was equal with both the drugs after oral administration. Several children in midazolam group completed the procedure without achieving desired level of sedation and none of the children in triclofos group did so. Several children required supplementation with intravenous midazolam in both groups and success rate after this was better in triclofos group. Midazolam was associated with faster onset, shorter duration of sedation and more rapid recovery. No child in both groups had any adverse event.

No previous studies are available where intravenous midazolam was used to supplement oral midazolam to improve success rate. At the time of carrying out the study syrup preparation of oral midazolam were not available. Further studies can be done with syrup preparation.

\section{Conclusion}

We conclude that both drugs were equally effective and 
safe for CT scan in children. However better recovery profile of midazolam makes it suitable for day care procedures like CT scan.

\section{Funding: $\mathrm{Nil}$}

\section{Acknowledgments: Nil}

Conflict of interest: No stated conflict of interest among the authors

\section{References}

1. Vade A, Sukhani R, Dolenga M, Habisohn-Schuck C. Chloral Hydrate Sedation of Children undergoing CT and MR Imaging:Safety as Judged by American Academy of Pediatric Guidelines. AJR 1995;165:905-9.

2. Schmalfuss I. Oral sedation of pediatric patients for noninvasive radiological procedures:chloral hydrate versus midazolam. Journal of radiology nursing 2005;24:42-8.

3. Malviya S, Vopel-Lewis T, Prochaska G, Tait AR. Prolonged recovery and delayed side effects of sedation for diagnostic imaging studies in children. Pediatrics 2000;105:E42.

4. Gozal D, Dregenger B, D Levin PD, BChir MB, KadariA, Gozal Y. A pediatric sedation/anesthesia programme with dedicated care by anesthesiologists and nurses for procedures outside the operating room. J Pediatr 2004;145:47-52.

5. McMillan CO, Spahr-Schopfer IA, Sikich N, Hartley E, Lerman J. Premedication of children with oral midazolam. Can J Anesth 1992;39;545-50.

6. D’Agostino J, Temdrup TE. Chloral Hydrate versus Midazolam for sedation of children for neuroimaging: A randomized clinical trial. Pediatric Emergency care 2000;16:1-5.

7. Ramsay MA, Savege TM, Simpson BR, Goodwin R. Controlled sedation with alphaxalone-alphadolone. Br Med J 1974;2:656-9.

8. Aldrete JA, Kroulik D. A Postanesthetic Recovery Score. Anesthesia and Analgesia current researches 1970;49:924-34.

9. Parameswari A, Maheedar G, Vakamudi M. Sedative and Anxiolytic Effects of Midazolam and Triclofos Oral premedication in children Undergoing Elective Surgery: A Comparison. J Anaesth Clini Pharmacol 2010;26:340-4

10. Feld LH, Negus JB, White PF. Oral Midazolam Preanesthetic Medication in Pediatric Outpatients. Anesthesiology 1990;73:831-4.

11. Davies FC,Waters M. Oral midazolam for conscious sedation of children during minor procedures. J Accid Emerg Med 1998;15:2448 .

12. Singh N, Pandey RK, Saksena AK, Jaiswal JN. A comparative evaluation of oral midazolam with other sedatives as premedicant in pediatric dentistry. J Clin Pediatr Dent 2002;26:161-4.

13. Cagiran E, Eyigor C, Sipahi A, Koca H, Balcioglu T, Uyar M. Comparison of oral midazolam and midazolam - ketamine as sedative agents in pediatric dentistry. Eur J Pediatric Dent 2010;11:19-22.
14. Roach CL, Hussain N, Zabinsky J, Wwlch E, Garg R. Moderate sedation for echocardiography of preschoolers. Pediatr Cardiol 2010;31:469-73.

15. Brosius KK, Bannister CF. Midazolam Premedication in children: comparison of two oral dosage formulations on sedation score and plasma midazolam levels. Anesth analg 2003;96:392-5.

16. Payne K, Matheyse FJ, Liebenberg D, Dawas T. The pharmacokinetics of midazolam in pediatric patients. Eur J Clin Pharmacol 1989;37:267-72.

17. Singh R, Kumar N, Vajifdar H. Midazolam as sedative for computed tomography imaging in pediatric patients. Pediatric Anesthesia 2009;19:899-904. 